\title{
Article \\ Characteristics of Soil Respiration and Its Components of a Mixed Dipterocarp Forest in China
}

\author{
Jun-Fu Zhao ${ }^{1,+}{ }^{+}$Zhi-Yong Liao ${ }^{2,+}{ }^{\oplus}$, Lian-Yan Yang ${ }^{3}$, Jian-Kang Shi ${ }^{1}$ and Zheng-Hong Tan ${ }^{4, *}$ \\ 1 Hainan Provincial Ecological and Environmental Monitoring Centre, Haikou 571126, China; \\ hnuzhao@sina.com (J.-F.Z.); stanking16888@163.com (J.-K.S.) \\ 2 CAS Key Laboratory of Tropical Forest Ecology, Xishuangbanna Tropical Botanical Garden, \\ Chinese Academy of Sciences, Mengla 666303, China; liaozy@xtbg.org.cn \\ 3 Ecology Program, School of Ecology \&Environment, Hainan University, Haikou 570228, China; \\ yly@hainu.edu.cn \\ 4 School of Ecology and Environmental Sciences, Yunnan University, No.2 North Cuihu Road, \\ Kunming 650091, China \\ * Correspondence: tanzh@xtbg.ac.cn \\ + These authors contributed equally.
}

Citation: Zhao, J.-F.; Liao, Z.-Y.; Yang, L.-Y.; Shi, J.-K.; Tan, Z.-H. Characteristics of Soil Respiration and Its Components of a Mixed Dipterocarp Forest in China. Forests 2021, 12, 1159. https://doi.org/ $10.3390 /$ f12091159

Academic Editor: Megan

E. McGroddy

Received: 8 July 2021

Accepted: 24 August 2021

Published: 27 August 2021

Publisher's Note: MDPI stays neutral with regard to jurisdictional claims in published maps and institutional affiliations.

Copyright: (c) 2021 by the authors Licensee MDPI, Basel, Switzerland. This article is an open access article distributed under the terms and conditions of the Creative Commons Attribution (CC BY) license (https:/ / creativecommons.org/licenses/by/ $4.0 /)$

\begin{abstract}
Background: Although numerous studies have been carried out in recent decades, soil respiration remains one of the less understood elements in global carbon budget research. Tropical forests store a considerable amount of carbon, and a well-established knowledge of the patterns, components, and controls of soil respiration in these forests will be crucial in global change research. Methods: Soil respiration was separated into two components using the trenching method. Each component was measured at multiple temporal scales and in different microhabitats. A commercial soil efflux system (Li8100/8150) was used to accomplish soil respiration monitoring. Four commonly used models were compared that described the temperature dependence of soil heterotrophic respiration using nonlinear statistics. Results and Conclusions: Trenching has a limited effect on soil temperature but considerably affects soil water content due to the exclusion of water loss via tree transpiration. Soil respiration decreased gradually from 8 to $4 \mu \mathrm{mol} \cdot \mathrm{m}^{-2} \cdot \mathrm{s}^{-1} 6$ days after trenching. Soil autotrophic $\left(R_{a}\right)$ and heterotrophic respiration $\left(R_{h}\right)$ have contrasting diel patterns and different responses to temperature. $R_{h}$ was negatively correlated with temperature but positively correlated with relative humidity. Both $R_{a}$ and $R_{h}$ varied dramatically among microhabitats. The $Q_{10}$ value of $R_{h}$ derived using the $Q_{10}$ model was 2.54 . The Kirschbaum-O'Connell model, which implied a strong decrease of $Q_{10}$ with temperature, worked best in describing temperature dependence of $R_{h}$. Heterotrophic respiration accounted for nearly half of the total soil efflux. We found an unexpected diurnal pattern in soil heterotrophic respiration which might be related to diurnal moisture dynamics. Temperature, but not soil moisture, was the major controller of seasonal variation of soil respiration in both autotrophic and heterotrophic components. From a statistical perspective, the best model to describe the temperature sensitivity of soil respiration was the Kirschbaum-O'Connell model. Soil respiration varied strongly among the microhabitats and played a crucial role in stand-level ecosystem carbon balance assessment.
\end{abstract}

Keywords: microhabitat; diurnal pattern; temperature sensitivity; moisture; carbon sink

\section{Introduction}

Soil respiration is an important process in carbon cycle of terrestrial ecosystems. Numerous studies have been carried out to investigate topics of soil respiration or efflux, from tropical to boreal forests [1,2]. However, current knowledge on soil respiration is still poor compared to that on photosynthesis. It is necessary to achieve a process-based model on soil respiration which is similar to photosynthesis biochemical models [3].

Tropical forest, where a warm and wet climate drives fast biogeochemical turnover, plays a major role in global carbon cycling and, hence, the rate of climatic warming [4]. 
Nevertheless, soil respiration studies on tropical forests are much fewer in number than those on boreal or temperate forests [5-7]. In the tropical forests near the equator, the annual temperature range is small compared to boreal or temperate forests. The common temperature dependence of soil respiration in other biomes was not detected in these equatorial tropical forests [8,9]. Even in the case of tropical seasonal forests, soil respiration was found not related to temperature [10-12]. This hindered the assessment of temperature sensitivity in tropical soil respiration, an important parameter in climatic and biogeochemical models.

Soil respiration is the sum of autotrophic respiration by plant roots and heterotrophic respiration by soil microbes. Since different organisms are involved in these two componential processes, they might respond differently to environmental changes. Thus, it is necessary to separate them when carrying out soil respiration studies. However, such steps have seldom been taken in previous studies on tropical soil respiration.

To investigate the pattern, components, and controls of tropical forest soil respiration, we used the trenching method and measured the two componential processes of soil respiration in a mixed dipterocarp forest in China. The specific aims of the study were (1) to determine temperature sensitivity and the best model describing this sensitivity, (2) to separate respiration into autotrophic and heterotrophic components, as well as investigate their patterns and controls, and (3) to investigate how soil respiration varies among microhabitats. In the mixed dipterocarp forest, the annual temperature range could be up to $10^{\circ} \mathrm{C}$; thus, it was feasible to achieve our objects in our study site.

\section{Materials and Methods}

\subsection{Site Description}

The experiment was carried out in a dipterocarp forest on the northern edge of tropical Southeast Asia, in Xishuangbanna, China, at $21^{\circ} 37^{\prime} \mathrm{N}, 101^{\circ} 35^{\prime} \mathrm{E}$ [13]. The climate of this area shows strong seasonality. A local meteorologist divided the whole year into three sub-seasons: the dry hot season (March and April), fog cool season (November through February next year), and rainy season (May through October) [14]. Climatic records over the past 50 years showed a mean annual total rainfall of about $1500 \mathrm{~mm}, 87 \%$ of which occurred in the rainy season. The remaining 13\% (195 mm) occurred in the dry half of the year, when the monthly rainfall was usually less than $50 \mathrm{~mm}$. Mean annual air temperature is around $21.8^{\circ} \mathrm{C}$, while the coldest monthly mean temperature is below $15^{\circ} \mathrm{C}$ and cold fronts can lower the temperature to $2-4{ }^{\circ} \mathrm{C}$.

The forest being studied here is a primary mixed dipterocarp forest, referred to by local vegetation scientists as a tropical seasonal rainforest (Figure 1). This forest is famous for its particularly tall trees which can reach heights of $60-70 \mathrm{~m}$. The forest canopy is very complex with multiple layers. A closed canopy exists at $25-35 \mathrm{~m}$, while emergent trees (mostly Shorea wantianshuea) reach 60-70 m. The mean diameter at breast height is $5.69 \mathrm{~cm}$, and the mean total basal area for trees with a diameter at breast height above $1.0 \mathrm{~cm}$ is $42.34 \mathrm{~m}^{2}$ per hectare. The mean stand biomass is $421 \mathrm{t}$ of dry matter per hectare, which is close to the biomass levels in equatorial rainforest in Pasoh [13,15]. The presence of large logs, many epiphytes, an uneven age distribution, and complex canopy characterizes the forest as "old growth". The soil is lateritic, derived from siliceous rocks such as granite and gneiss, with $\mathrm{pH}$ from 4.91 , and the organic matter content of the $0-20 \mathrm{~cm}$ mineral soil layer is approximately $20 \mathrm{~g} \cdot \mathrm{kg}^{-1}$. [15]. A 20 ha permanent plot was established in 2007 for the purpose of studying the structure and dynamics of the dipterocarp forest. 

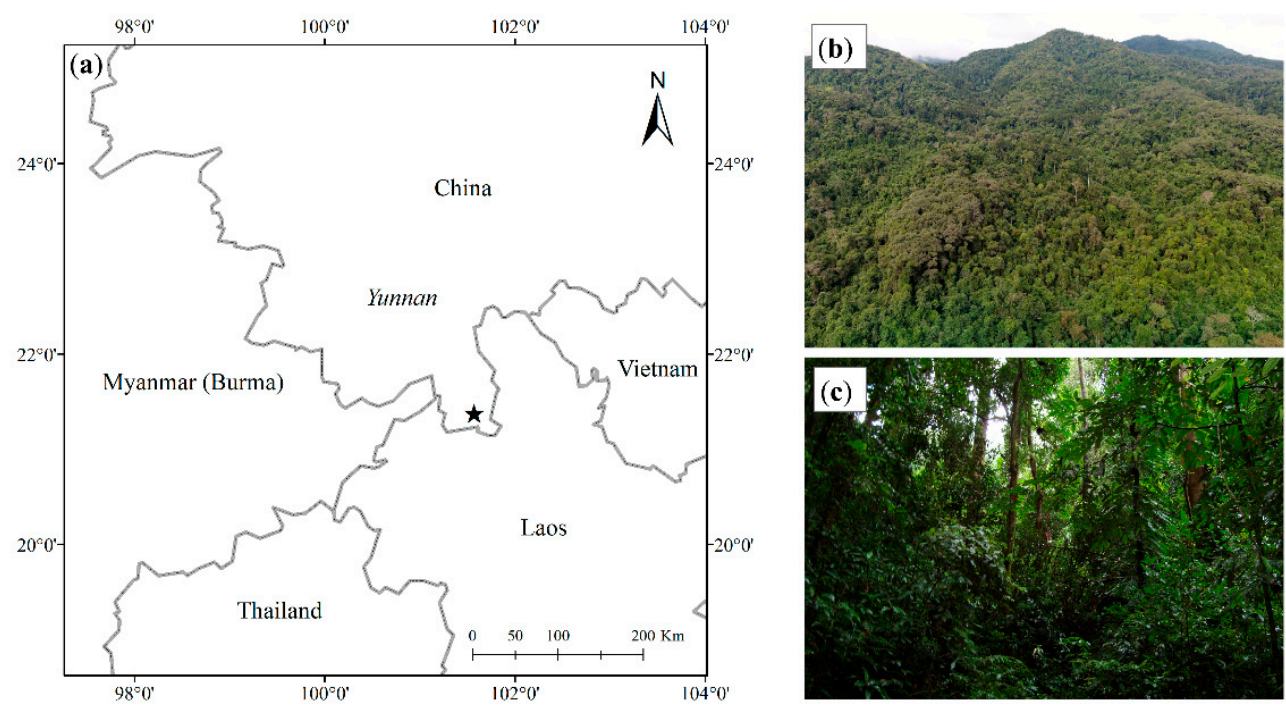

Figure 1. Site location ( $\star$ ) and the landscape: (a) site location; (b) canopy; (c) understory.

\subsection{Experimental Design}

The studied forest is located in a mountainous area [13] (cf. Figure 2 in terrain map), and the terrain is very complex (Figure 1). The elevation gradient of this area varies from 709 to $869 \mathrm{~m}$ above sea level. Different microhabitats exist due to changes in micro-terrain. It is noted that forest soil respiration has strong spatial heterogeneity, and the degree of variation could be enforced by the complex micro-terrain [15]. Taking representative measurements in this area is a challenging task, and each microhabitat should be considered.
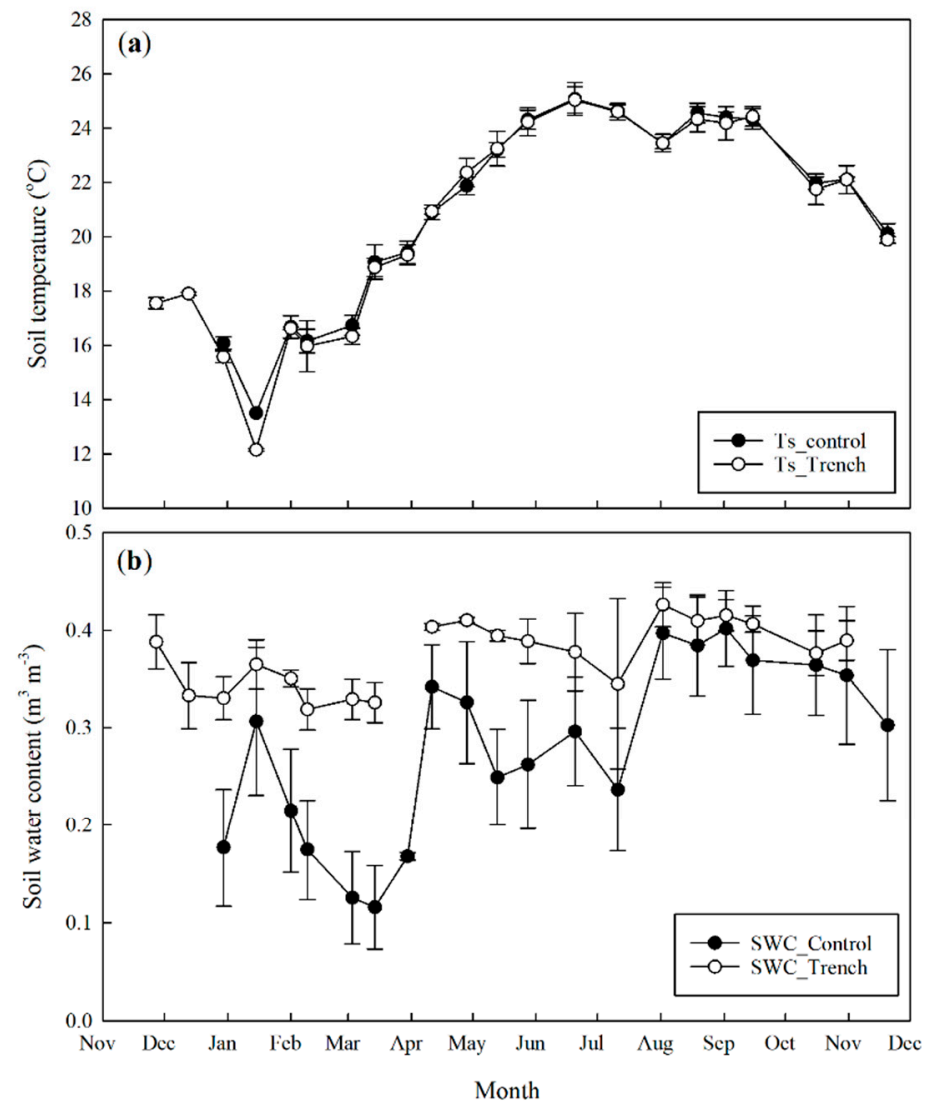

Figure 2. Temporal dynamics of soil temperature (a) and soil water content (b). Both soil temperature and soil water content were measured at a depth of $5 \mathrm{~cm}$. Error bars represent standard deviation. 
We firstly chose a small low-elevation hill as the target site for soil respiration in this study. The small hill has an area of around $60 \times 50 \mathrm{~m}$ and is irregular in shape. The slope is gentle (around 6-15 degree) in this small hill. Below the hill is a watershed stream and a small pond. We chose this small low-elevation hill as the study site, considering the representativeness of this site and the difficulties in placing soil respiration instruments, here the Li-8150, at sites with steep slopes.

The small hill was classified into the following three microhabitats: (1) forest gap (Plot \#1); (2) upper slope (Plot \#2); (3) lower slope valley (Plot \#3). There is a new forest gap in the lower-slope position of the target hill; thus, we set up Plot \#1 near this gap. The upper-slope microhabitat (Plot \#2) has little organic litter on the floor as the runoff flow of rain could drive the litter and nutrients to the lower habitats. Thus, it could be viewed as a nutrient- and organic-poor habitat. The lower-slope habitat, on the contrary, has a relatively thick decaying litter, and the soil surface looks darker than that of the upper-slope habitat.

In each microhabitat, we set up two paired plots. One plot was trenched, and the paired plot within the same habitat was treated as a control. The plot was $3 \times 3 \mathrm{~m}$ in size. The $50 \mathrm{~cm}$ wide trench had a depth of 120-130 cm. The trench was refilled with the excavated soil. In order to avoid root growth into the plot, four high-quality plexiglass sheets were erected in the trench of each plot. We believed that this trench depth could cut off all roots in this study forest, as no roots were visible at this depth. Soil was hard and rock was semi-weathered at this depth. In the center of each plot, we randomly placed 3-4 collars for soil measurements.

\subsection{Measurements of Soil Respiration and Microclimatic Factors}

A commercial soil efflux system was used to measure soil respiration and microclimatic factors. Some of the self-made soil efflux chambers used fans to mix air in the chamber during measurement. However, it has been experimentally established that soil efflux rates increase linearly with wind speed [16]. The Li-8100/8150 multiplexer automatic soil $\mathrm{CO}_{2}$ flux system (Li-Cor Inc, Lincoln, NE, USA) selected for this study has a special design that avoids the use of fans during measurement [17].

The Li-8150, connected with eight chambers, was used three times. The first time was to monitor how soil respiration changed during and after trenching. The second and third times were to monitor diurnal variation during the dry and rainy seasons. The second measurement ran from 22 March 2015 to 29 March 2015. Data from the third set of measurements were not used here for experimental reasons. Air relative humidity data were collected from a nearby tower in the same time period.

The Li-8100 was used to carry out regular soil respiration measurements twice a month for detecting seasonal patterns and for annual sum estimation. Each time, soil respiration measurements were started at 11:00 a.m. and lasted until 1:00 p.m. Each collar was measured three times. Soil water content $\left(S_{\mathrm{WC}}\right)$ and soil temperature $\left(T_{S}\right)$ were measured at the same time with sensors provided by the manufacturers.

\subsection{Definition and Calculations}

The commercial efflux system provides calculated soil carbon dioxide flux by either linear or exponential fitting of the $\mathrm{CO}_{2}$ concentration to time (cf. Li-Cor 8100/8150 manual). We did not carry out further recalculations but adopted the values generated by the system. Soil carbon dioxide flux measured in the control and trench treatment were regarded as total soil respiration $\left(R_{S}\right)$ and heterotrophic respiration $\left(R_{h}\right)$, respectively. Autotrophic respiration $\left(R_{a}\right)$ was calculated as the difference between $R_{s}$ and $R_{h}$. The annual sum of respiration was extrapolated by integrating with time. 


\subsection{Models for Temperature Response of Soil Respiration}

There are four commonly used models in describing temperature dependence of soil heterotrophic respiration $\left(R_{h}\right)$ :

$$
\begin{gathered}
R_{h}=R_{10} Q_{10}^{[(T-10) / 10]}, Q_{10} \text { model, } \\
R_{h}=R_{10} \exp \left[\frac{E_{a}}{R}\left(\frac{1}{10+273.15}-\frac{1}{T+273.15}\right)\right], \text { Arrhenius model, } \\
R_{h}=\alpha \exp \left[E_{0}\left(\frac{1}{283.15-T_{0}}-\frac{1}{T_{K}-T_{0}}\right)\right], \text { Lloyd-Kavanau model, } \\
R_{h}=\alpha \exp \left[\beta T\left(1-0.5 \frac{T}{T_{m}}\right)\right], \text { Kirschbaum-O/Connell model, }
\end{gathered}
$$

where $R_{10}$ is the reference respiration at $10{ }^{\circ} \mathrm{C}, \mathrm{T}$ is the driving temperature, $T_{K}$ is the driving temperature in units of Kelvin, $Q_{10}$ is the temperature sensitivity index defined as $Q_{10}=\frac{R_{h}(T+10)}{R_{h}(T)}, E_{a}$ is the activation energy, $R$ is the gas constant $\left(8.314 \mathrm{~J} \cdot \mathrm{mol}^{-1} \cdot \mathrm{K}^{-1}\right), \alpha, \beta$, and $T_{m}$ are fitted parameters, $E_{0}$ is a similar but loose term of activation energy $E_{0} \approx \frac{E_{a}}{R T_{K}}$, and $T_{0}$ is a fitted parameter, the initial value of which needs to be lower than any observed temperature when applying nonlinear regression.

The $Q_{10}$ expression for each model is as follows:

$$
\begin{gathered}
Q_{10} \text { model : } Q_{10}=\text { Cons, } \\
\text { Arrhenius model : } Q_{10}=\exp \left(\frac{10 E_{a}}{R T(T+10)}\right), \\
\text { Lloyd-Kavanau model : } Q_{10}=\exp \left(\frac{10 E_{0}}{\left(T-T_{0}\right)\left(T+10-T_{0}\right)}\right), \\
\text { Kirschbaum-O/Connell model : } Q_{10}=\exp \left(10 \beta\left(1-\frac{T}{T_{m}}\right)-\frac{50 \beta}{T_{m}}\right),
\end{gathered}
$$

where Cons indicates a constant.

All nonlinear regressions in the study were performed using Matlab 7.1 (Mathworks Inc., Natick, MA, USA). We used the determinant coefficient $\left(r^{2}\right)$ and sum of residual squares (SSR) to assess goodness of fit. The upper and lower $95 \%$ confidential intervals of each fitted parameter were provided.

\section{Results}

\subsection{Trench Effect on Soil Microclimate and Soil Respiration}

Trenching had a limited effect on soil temperature $\left(T_{s}\right)$. There was no difference in $T_{s}$ between control and trenching treatments (Figure 2a). On the contrary, the effect of trenching on soil water content $\left(S_{W C}\right.$ ) was very strong (Figure $2 b$ ). The $S_{W C}$ did not drop even during the driest period in trenching plots.

The effect of trenching on soil respiration was obvious (Figure 3). Average $R_{S}$ decreased from $8 \mu \mathrm{mol} \cdot \mathrm{m}^{-2} \cdot \mathrm{s}^{-1}$ to $4 \mu \mathrm{mol} \cdot \mathrm{m}^{-2} \cdot \mathrm{s}^{-1}$ after trenching. This decrease was a gradual process lasting several days.

\subsection{Diel Variation of Soil Respiration and Its Components}

There were clear diel patterns in soil respiration and its components (Figure 4). Heterotrophic respiration $\left(R_{h}\right)$ decreased from the highest level in the early morning to the lowest level in the late afternoon during the daytime, and then it increased to the highest level in the early morning during the nighttime. This pattern was similar to the pattern of relative humidity $\left(H_{r}\right)$, but not to that of soil temperature $\left(T_{s}\right)$ (Figure $4 \mathrm{~d}$ ). A significant positive correlation was found between $R_{h}$ and $H_{r}(r=0.69, p<0.001)$, whereas a significant negative correlation was found between $R_{h}$ and $T_{\mathrm{S}}(r=-0.64, p<0.001)$. 


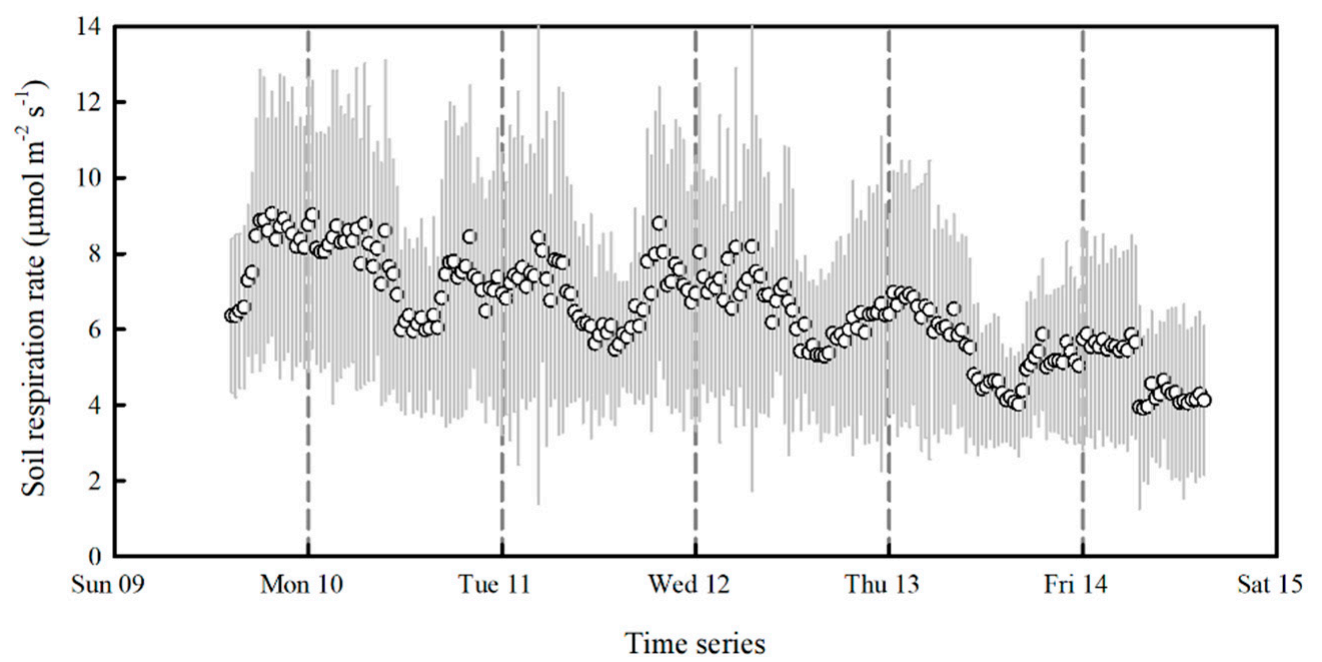

Figure 3. A continuous monitoring of soil respiration rate to show the effect of trenching. Gray shading indicates the standard deviation.
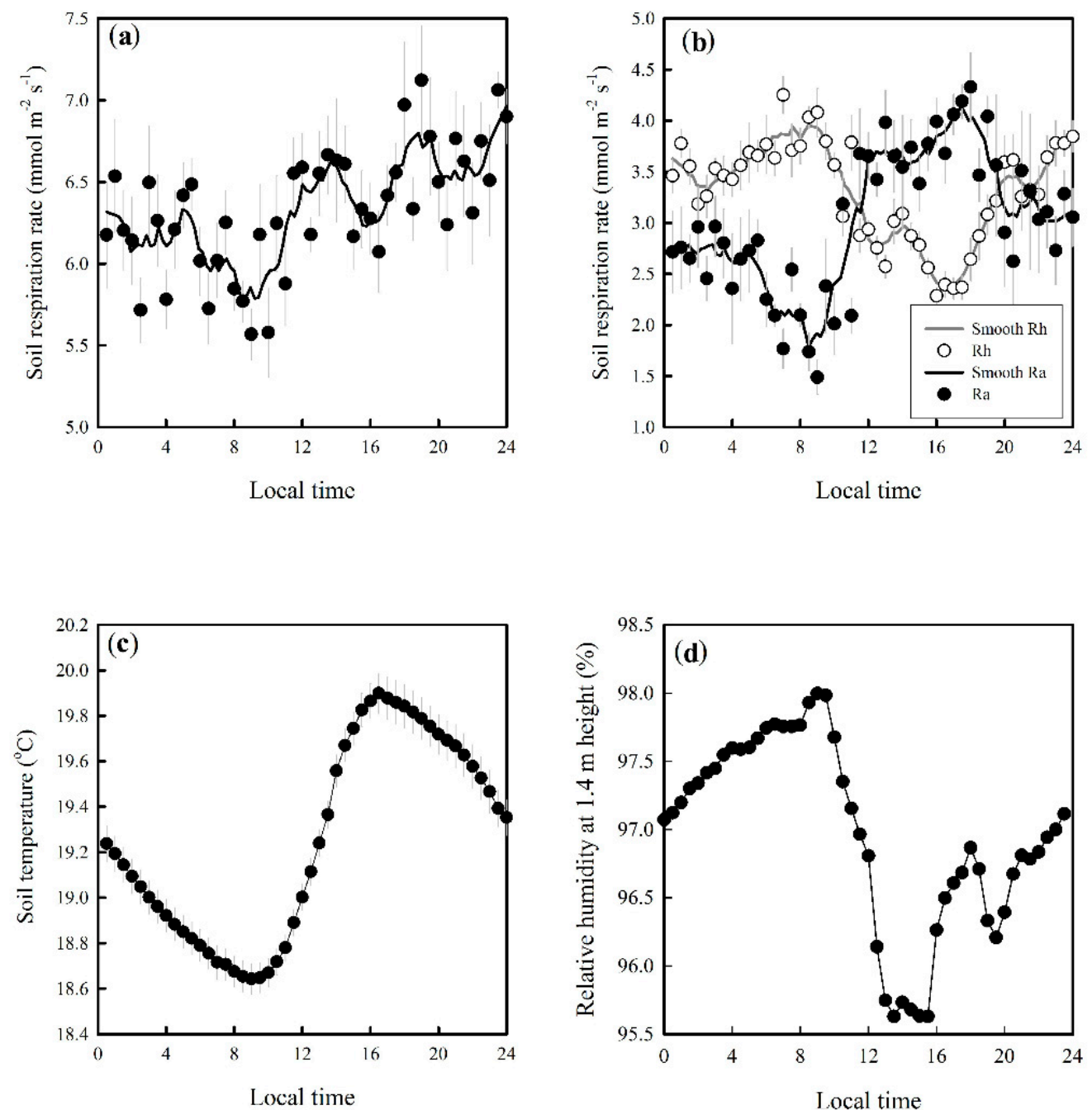

Figure 4. The diurnal variation of soil respiration (a), its components (b), soil temperature (c), and relative humidity of air at $1.4 \mathrm{~m}$ height $(\mathrm{d}) . R_{h}$ : heterotrophic respiration in the trenching treatment; $R_{a}$ : autotrophic respiration calculated as the difference between total soil respiration and $R_{h}$. Error bars indicate the standard deviation. 
Autotrophic respiration $\left(R_{a}\right)$ exhibited an opposite diel pattern to that of $R_{h} . R_{a}$ was highest in the late afternoon. There was a continuous decrease in $R_{a}$ during the nighttime. A significant positive correlation was found between $R_{a}$ and $T_{S}(r=0.77, p<0.001)$. The diurnal range of $R_{a}\left(\sim 3 \mu \mathrm{mol} \cdot \mathrm{m}^{-2} \cdot \mathrm{s}^{-1}\right)$ was higher than that of $R_{h}\left(\sim 1.5 \mu \mathrm{mol} \cdot \mathrm{m}^{-2} \cdot \mathrm{s}^{-1}\right)$. Total soil respiration $\left(R_{s}\right)$ exhibited a similar pattern to that of $R_{h}$ and was significantly correlated to $T_{S}(r=0.58, p<0.001)$.

\subsection{Variation in Soil Respiration across Seasons and Microhabitats}

Both $R_{s}$ and $R_{h}$ varied dramatically in different microhabitats, with a clear seasonal pattern (Figure 5). The lowest $R_{s}$ and $R_{h}$ were observed in the upper-slope microhabitat. The gap plot showed the highest $R_{s}\left(10.07 \pm 3.90 \mu \mathrm{mol} \cdot \mathrm{m}^{-2} \cdot \mathrm{s}^{-1}\right)$. Highest $R_{h}$ was observed in the lower-slope valley microhabitat $\left(5.27 \pm 1.96 \mu \mathrm{mol} \cdot \mathrm{m}^{-2} \cdot \mathrm{s}^{-1}\right)$. The highest $R_{s}$ values could be as high as three times the lowest values. The $R_{h}$ in the valley habitat was twice as high as that in the upper-slope habitat.

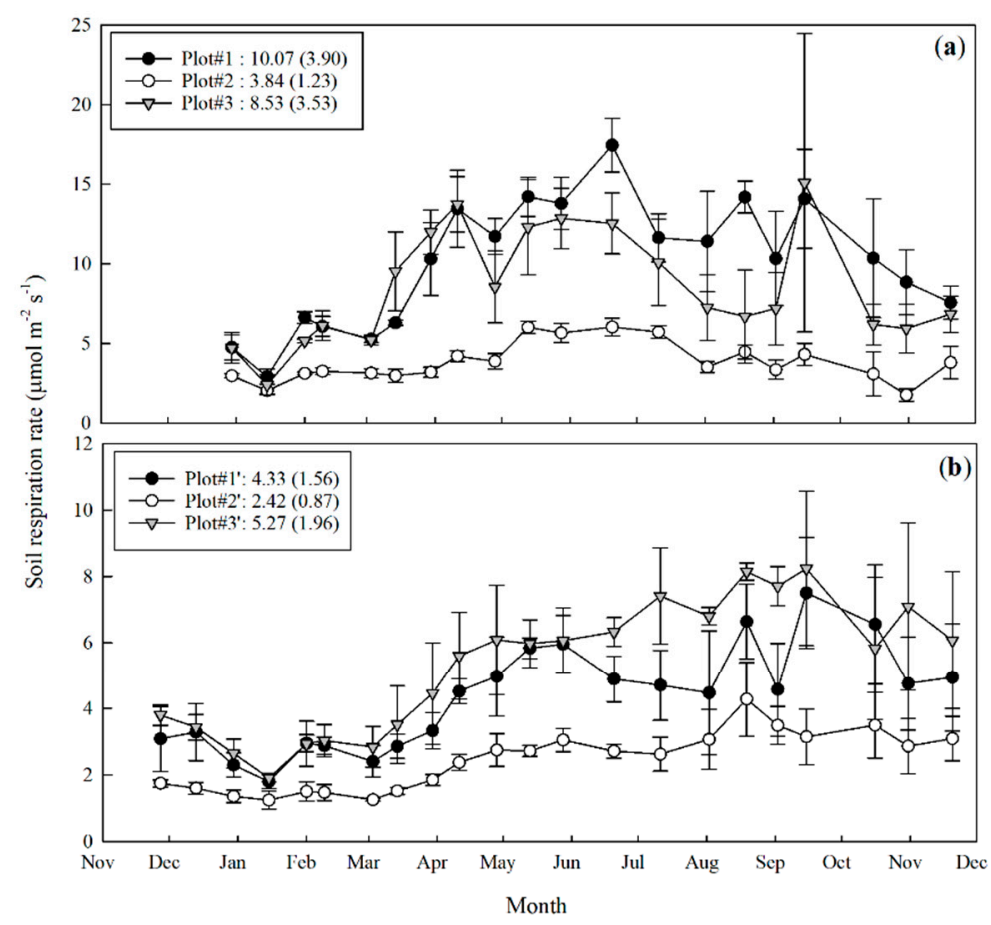

Figure 5. Soil respiration rate of the paired plots in control (a) and trenching treatment (b). Plot \#1 and Plot \#1 $1^{\prime}$ are paired plots in forest gap; Plot \#2 and Plot \#2' are paired plots in upper slope; Plot \#3 and Plot \#3' are paired plots in lower slope valley. Error bars represent the standard deviation.

\subsection{Temperature Sensitivity of Soil Respiration}

Soil respiration, especially the heterotrophic component $\left(R_{h}\right)$, was highly correlated to temperature in the studied forest (Figure 6). The $Q_{10}$ value of $R_{h}$ derived using the $Q_{10}$ model was 2.54. From a statistical perspective, however, the $Q_{10}$ model did not provide the best description of the temperature dependence of $R_{h}$ (Table 1). The Kirschbaum-O'Connell model which implied a strong decrease in $Q_{10}$ with temperature fit the best (Figure 7 and Table 1). The $Q_{10}$ values derived using the four models converged at a temperature around $16^{\circ} \mathrm{C}$ (Figure 7). The $Q_{10}$ value at the mean annual temperature $\left(22^{\circ} \mathrm{C}\right)$ varied dramatically among models. It was 2.54, 2.40, 1.79, and 1.01 for the $Q_{10}$, Arrhenius, Lloyd-Kavanau, and Kirschbaum-O'Connell models, respectively. 

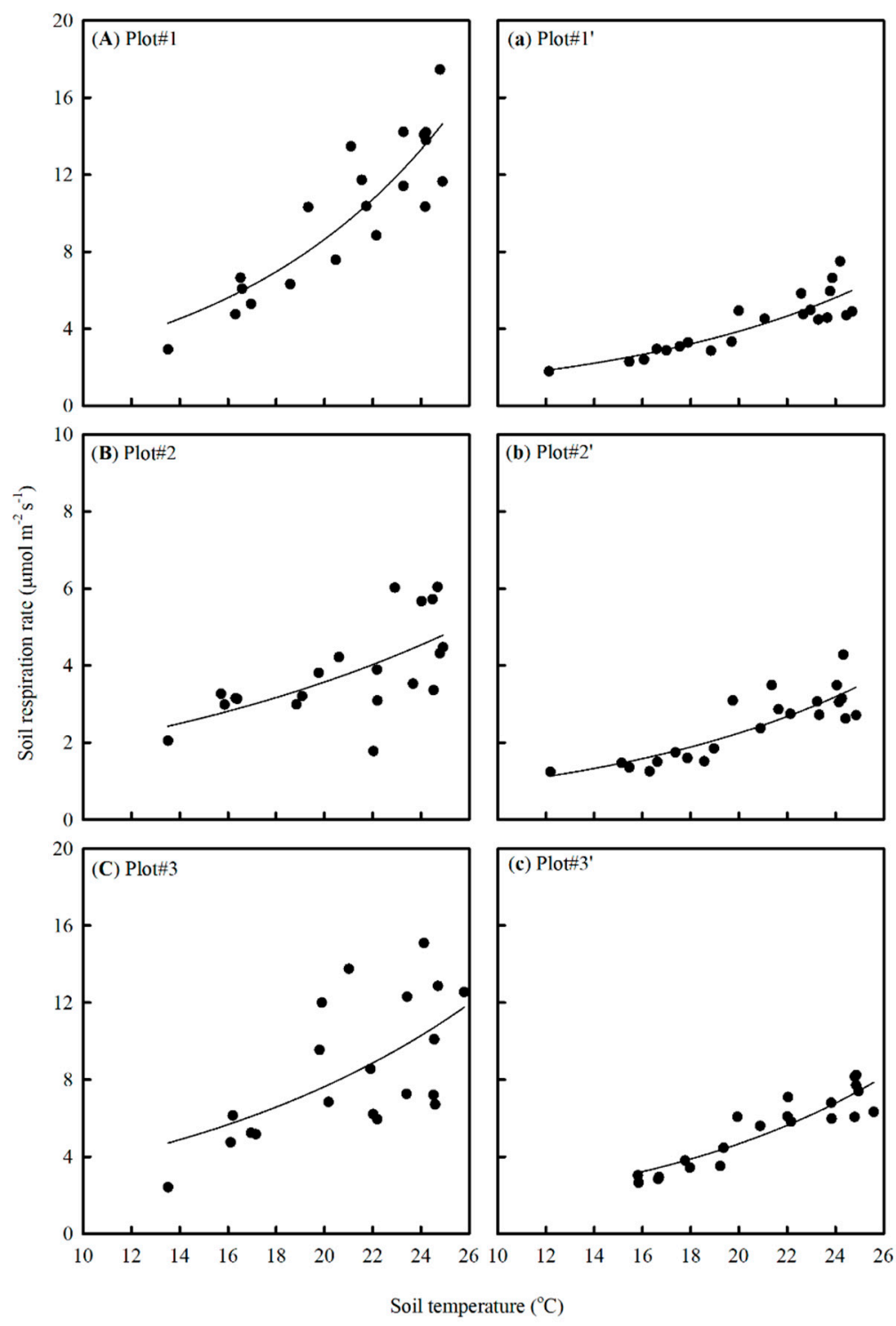

Figure 6. Temperature response of soil respiration rate for the paired plots in different treatments. Plots \#1-3 are control treatments; Plots \#1'-3' are trench treatments. Plots \#1-3 are paired to Plots $\# 1^{\prime}-3^{\prime}$ from the forest gap, upper slope, and lower slope valley, respectively. The regression line was fitted using a two-parameter exponential growth equation.

Table 1. Summary table for comparison of the fitting of four models for soil heterotrophic respiration. Values in parentheses are $95 \%$ confidential intervals of each estimated parameter; $r^{2}$ represents the determinant coefficient; SSE is the sum of squared errors.

\begin{tabular}{|c|c|c|c|c|c|}
\hline Model Type & $r^{2}$ & SSE & $\alpha, R_{10}$ & $Q_{10}, E_{a}, E_{0}, \beta$ & $T_{0}, T_{m}$ \\
\hline$Q_{10}$ & 0.8370 & 6.8438 & $\begin{array}{c}1.4254 \\
(1.0161,1.8347)\end{array}$ & $\begin{array}{c}2.5474 \\
(1.9729,3.1219)\end{array}$ & \\
\hline Arrhenius & 0.8394 & 6.7401 & $\begin{array}{c}1.3761 \\
(0.9718,1.7803)\end{array}$ & $\begin{array}{c}65,723 \\
(49,964,81,481)\end{array}$ & \\
\hline Lloyd-Kavanau & 0.8543 & 6.1016 & $\begin{array}{c}0.6879 \\
(-0.5530,1.9289)\end{array}$ & $\begin{array}{c}50.68 \\
(-97.45,198.81)\end{array}$ & $\begin{array}{c}270.20 \\
(237.33,303.08)\end{array}$ \\
\hline Kirschbaum-O'Connell & 0.8643 & 5.6964 & $\begin{array}{c}0.0246 \\
(-0.0602,0.1095)\end{array}$ & $\begin{array}{c}0.4014 \\
(0.0673,0.7356)\end{array}$ & $\begin{array}{c}27.07 \\
(20.20,33.93)\end{array}$ \\
\hline
\end{tabular}




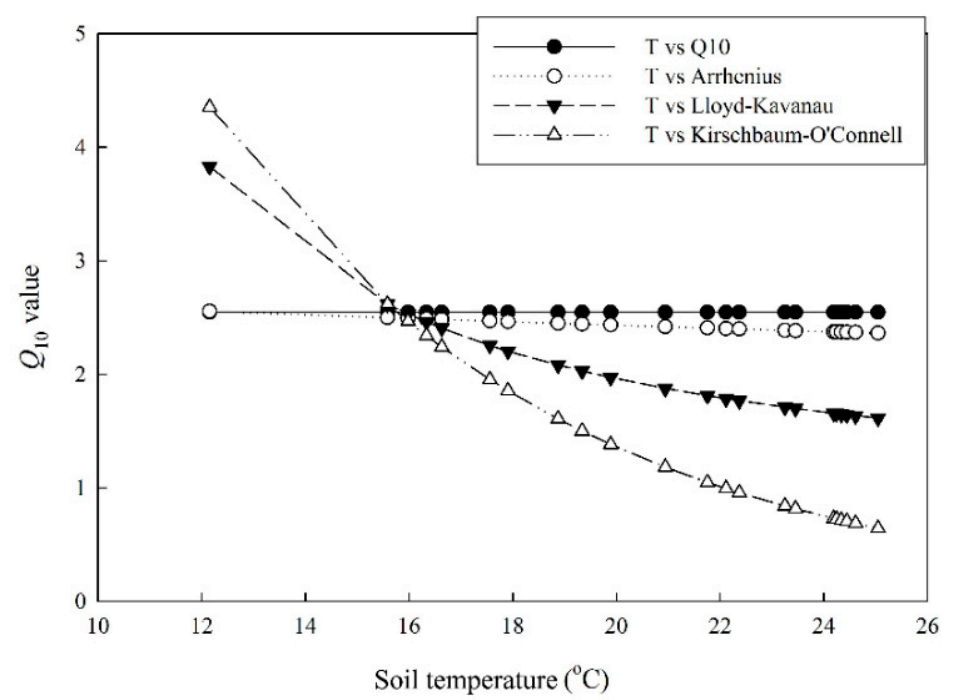

Figure 7. Soil temperature dependence of $Q_{10}$ derived using four different models.

\subsection{Contribution of autotrophic and heterotrophic components to total soil respiration}

The $R_{h}, R_{a}, R_{s}$ and $R_{h} / R_{s}$ all exhibit clear seasonal patterns (Figure 8 ). In general, $R_{a}$ and $R_{s}$ were higher during the rainy season. The $R_{h}$, however, increased from the beginning of the rainy season with no obvious decline until the end of the year. The overall mean contribution of $R_{h}$ to $R_{S}$ is $57.01 \%$. This implies that the contribution of $R_{h}$ is slightly higher than that of $R_{a}$ to $R_{s}$.
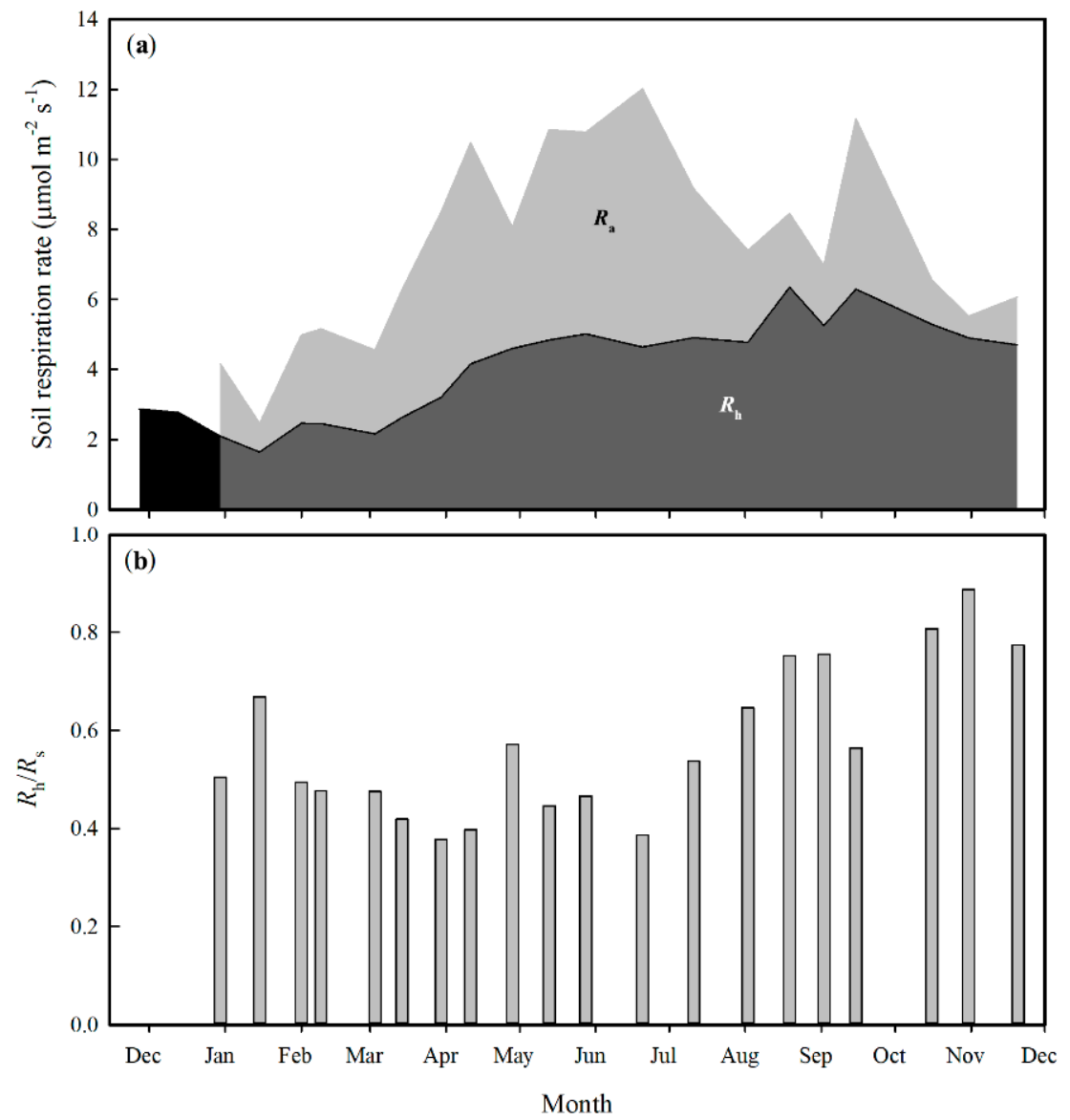

Figure 8. Temporal dynamics of soil respiration rate and its components (a), and of $R_{h} / R_{s}(\mathbf{b}) . R_{a}$ : autotrophic respiration, $R_{h}$ : heterotrophic respiration. 


\section{Discussion}

\subsection{The Unexpected Diel Pattern in Heterotrophic Respiration}

The effect of trenching on soil temperature was very small, but trenching had an obvious influence on soil water content and soil respiration. This was possibly due to the inhibition of transpiration and consumption of carbohydrates in roots. The existence of a hysteresis between temperature and soil respiration at a diurnal scale has been extensively reported [18]. Nevertheless, the reasons why hysteresis occurs between temperature and $R_{s}$ are still unknown. In our study, we separated $R_{s}$ into $R_{a}$ and $R_{h}$ using the trenching method and related them to soil temperature (Figure 9). We found contrasting diel patterns in $R_{h}$ and $R_{a}$, as well as in their responses to soil temperature. The diel pattern and its response to soil temperature of $R_{a}$ were consistent with previous findings [18]. However, the negative correlation between $R_{h}$ and $T_{s}$ was unexpected, and, to our knowledge, this is the first report of this new pattern.
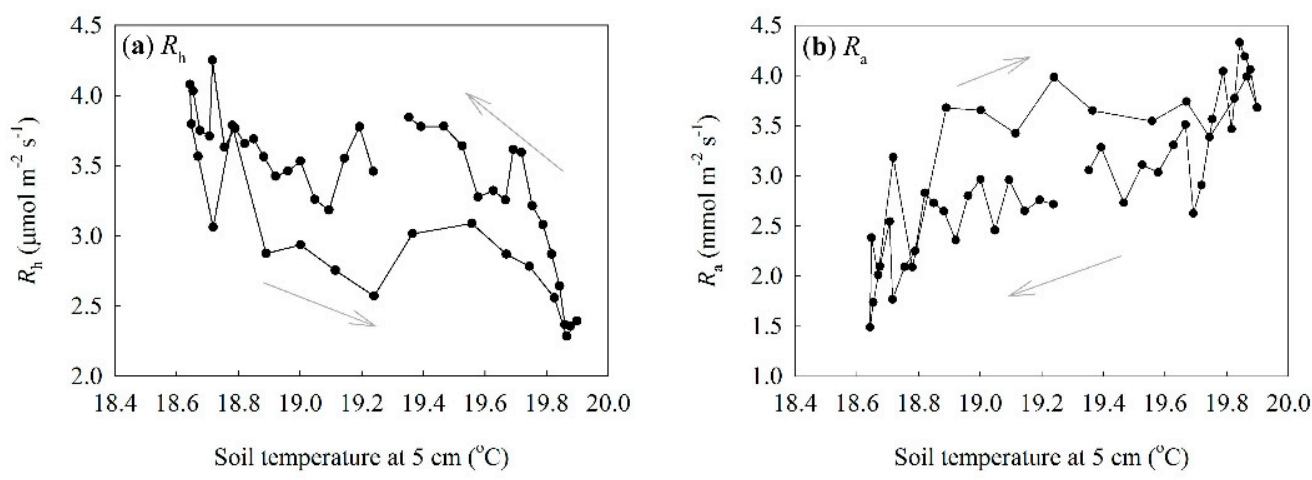

Figure 9. The relationship between soil temperature and soil respiration at diel scale: (a) variation of $R_{h}$ with soil temperature; (b) variation of $R_{a}$ with soil temperature.

We aimed to determine whether this unexpected new diel pattern in $R_{h}$ is a common pattern or not, and why it occurs. We compared our results with those collected in a tropical secondary forest in Thailand [11]. The lowest $R_{h}$ occurred after noon [11]. We also compared our results with unpublished data collected in Pasoh, Malaysia (data copyright reserved by Dr. Naishen Liang). The findings from Pasoh showed very similar results to those of this study. We, thus, suspect that this might be a common pattern in tropical forests of Southeast Asia. We further hypothesize that water condition is a major factor leading to the unexpected diel pattern in $R_{h}$. The major factors affecting $R_{h}$ could be summarized as temperature, water, and substrate $[19,20]$. The substrates for heterotrophic respiration include aboveground (e.g., leaves, branches) and belowground (e.g., dead roots) plant litter and soil organic matter. There is no evidence that these substrates vary significantly from day to night, although they do vary over longer time periods, such as seasonally and annually. Thus, substrate is not likely to account for this pattern. As shown before, there was a negative relationship between $R_{h}$ and $T_{s}$. This violates the basic principle of temperature-driving biochemical processes. Therefore, we could also exclude temperature as the cause for the observed pattern. Thus, the only factor remaining for consideration is water condition.

Evidence in support of the hypothesis that water condition is a major factor leading to the unexpected diel pattern in $R_{h}$ includes the following:

(i) We found a close relationship between $\mathrm{Rh}$ and relative humidity (Hr).

(ii) The climate in tropical forests could form a diel dry-and-rewet cycle on surface litter. Evaporation is strong in tropical rainforest because of the high year-round solar radiation and temperature [21,22]. High rates of evaporation dry the air, as well as surfaces of soil litter, during the day. On calm nights, radiation fog can form $[23,24]$ and air humidity increases. Litter surfaces can be rewetted during humid nights, representing one type of diel dry-and-rewet cycle. 
(iii) Litter may play an important role in soil carbon flux of tropical forests. A litterfall manipulation experiment in Costa Rican rainforest stressed the considerable role of litterfall in soil carbon cycling [25]. Litterfall, both as a direct source of CO2 and as an input of soil organic matter, should be expected to play an important role in soil heterotrophic respiration, especially in the rapid-turnover tropical rainforest [26,27].

\subsection{Temperature Sensitivity of the Studied Tropical Forests}

We have little information on temperature sensitivity of tropical forests except that collected from incubation studies [28,29]. The equatorial tropical forests have a narrow temperature range. Observations across seasons found a clear dependence of respiration upon water rather than temperature [8,9]. The studied tropical forest has an annual temperature range of up to $10{ }^{\circ} \mathrm{C}$, providing the possibility to investigate temperature sensitivity.

Many models have been used to describe the temperature dependence of soil respiration [30,31]. We compared four commonly used models to derive the temperature sensitivity index $\left(Q_{10}\right)$ of soil heterotrophic respiration (Table 1$)$. The $Q_{10}$ value derived from the $Q_{10}$ model was 2.54. Nevertheless, we found that the Kirschbaum-O'Connell model worked best in describing the temperature dependence from a statistical perspective. The Kirschbaum-O'Connell model stressed a steep decline in $Q_{10}$ with temperature (Figure 7). The reason why models implying a decrease in $Q_{10}$ with temperature work better than those with fixed $Q_{10}$ is still unknown. This might be related to substrate availability as suggested in modeling work [32].

The $Q_{10}$ of $R_{h}$ estimated using the $Q_{10}$ model (2.54) was higher than that collected from incubation studies, i.e., a forest in northern Southeast Asia (2.2) [28] and in Australia (1.43-2.21) [29]. The $Q_{10}$ value was also higher than that of the total soil respiration of a nearby non-dipterocarp forest (2.03-2.36) [33]. Soil water content was maintained at a near-saturation level across the seasons owing to the exclusion of transpiration water losses (Figure 2). The confounding effect of soil water content on $Q_{10}$ estimation was minimized. The $Q_{10}$ value here should, thus, be representative of the studied forest. This might be related to the latitude and mean annual temperature of this site. The site is close to the Tropic of Cancer with a mean annual temperature of around $22{ }^{\circ} \mathrm{C}$. Given that $Q_{10}$ decreases with mean annual temperature, the $Q_{10}$ of the studied forest was expected to be higher than that of forests closer to the equator [34].

\subsection{Variation of Soil Respiration among Microhabitats and Implications for Carbon Balance}

Topographic fragmentation is strong in the studied site [13], and spatial heterogeneity is an important dimension that needs to be taken into account under such circumstances [15]. Soil respiration of the three habitats varied strongly (Figure 5). The highest value was nearly three times that of the lowest. The arithmetical mean $R_{h}$ of the three microhabitats was $4.00 \mu \mathrm{mol} \cdot \mathrm{m}^{-2} \cdot \mathrm{s}^{-1}$, which can be easily extrapolated to $1516 \mathrm{gC} \cdot \mathrm{m}^{-2} \cdot \mathrm{year}^{-1}$. As reported before, the net primary production of this forest is $1198 \mathrm{gC} \cdot \mathrm{m}^{-2} \cdot \mathrm{year}^{-1}$ [13]. Thus, the studied forest was proposed as a net carbon source. However, this is not a convincing estimation. In fact, the forest gap only accounts for a small part of the total forest land [35]. A weighted averaging could produce a more sound estimation of soil respiration for the whole stand. We adopted a $20 \times 20 \mathrm{~m}$ resolution habitat classification map to accomplish the weight averaging [35]. Gap, low valley, and others accounted for $6.2 \%, 28.0 \%$, and $65.8 \%$ land area of the 20 ha plot, respectively. The weight-averaged soil heterotrophic respiration was $3.33 \mu \mathrm{mol} \cdot \mathrm{m}^{-2} \cdot \mathrm{s}^{-1}$ (equal to $1262 \mathrm{gC} \cdot \mathrm{m}^{-2} \cdot \mathrm{year}^{-1}$ ). This indicates a near-carbon-neutral state or a very slight carbon source for the studied forests. However, this remains a rough estimation because the microhabitats discussed here should be examined at a scale of several meters, as this is more reliable and convincing than the arithmetical averaging method.

Uncertainties arising from measuring techniques were slight in this study because of the following: 
(i) The use of the commercial Li-8100/8150 avoided the problem caused by fan mixing. Some self-design chambers use the convenience of fans for mixing [6]. This violates the basic principle of soil efflux measurement with the static chamber method [17]. Research has shown that soil CO2 efflux increases linearly with wind speed [16].

(ii) Sufficient trench depth: Trenching is still a major method used to separate soil heterotrophic and autotrophic respiration. Given insufficient trench depth, heterotrophic respiration cannot be completely separated [36]. We trenched to a depth of 1.2-1.3 m; at this depth, no visible root could be found, and rock was semi-weathered.

(iii) Reliability of the method used to calculate fluxes: Linear regression should be used appropriately in calculating CO2 efflux with a static chamber [37], as inappropriate application of this method could lead to serious bias. The present study avoided this bias (cf. Li-8100/8150 manual).

\section{Conclusions}

We investigated patterns, components, and controls of a mixed dipterocarp forest in China. Several conclusions could be drawn.

(i) Soil respiration varied strongly among the microhabitats and played a crucial role in stand-level ecosystem carbon balance assessment. A weight-averaged estimate taking this spatial variation into account could give more defensible soil respiration and net carbon budget assessment than arithmetical averaging.

(ii) The unexpected diel pattern on heterotrophic respiration was probably related to moisture dynamics.

(iii) The Kirschbaum-O'Connell model was the best model describing the temperature dependence of soil heterotrophic respiration among the four models. The temperature sensitivity index $\left(Q_{10}\right)$ varied among models. The value derived using the $Q_{10}$ model was 2.54 .

Author Contributions: Methodology and investigation, Z.-H.T., J.-F.Z. and Z.-Y.L.; writing—original draft preparation, J.-F.Z.; writing - review and editing, Z.-H.T. and Z.-Y.L.; data curation, J.-F.Z. and L.-Y.Y.; supervision, J.-K.S. All authors read and agreed to the published version of the manuscript.

Funding: This research was funded by the National Natural Science Foundation of China (no. 41771099,41861023 and 31660142) and the Hainan Province Key Research and Development Project (ZDYF2018171).

Acknowledgments: We sincerely thank the Xishuangbanna Station for Tropical Rain Forest Ecosystem Studies, especially Xiaofei Yang and Yun Deng, for their help with our field work.

Conflicts of Interest: The authors declare no conflict of interest.

\section{References}

1. Bond-Lamberty, B.; Thomson, S. Temperature-associated increases in the global soil respiration record. Nature 2010, 464, 579-582. [CrossRef]

2. Mukhortova, L.; Schepaschenko, D.; Moltchanova, E.; Shvidenko, A.; See, L. Respiration of Russian soils: Climatic drivers and response to climate change. Sci. Total. Environ. 2021, 785, 147314. [CrossRef]

3. Farquhar, G.D.; von Caemmerer, S.; Berry, J.A. A biochemical model of photosynthetic $\mathrm{CO}_{2}$ assimilation in leaves of $\mathrm{C}_{3}$ species. Planta 1980, 149, 78-90. [CrossRef]

4. Brown, S.; Lugo, A.E. The storage and production of organic matter in tropical forests and their role in the global carbon cycle. Biotropica 1982, 14, 161-187. [CrossRef]

5. Hashimoto, S.; Suzuki, M.; Inoue, A.; Takizawa, H.; Kosaka, I.; Tanaka, K.; Tantasirin, C.; Tangtham, N. Soil respiration and soil $\mathrm{CO}_{2}$ concentration in a tropical forest, Thailand. J. For. Res. 2004, 9, 75-79. [CrossRef]

6. Tan, Z.; Liang, N.; Zhang, Y.; Teramoto, M.; Yu, G.; Yan, J. Soil respiration of tropical forests: Overview and synthesis. J. Yunnan Univ. 2013, 35, 833-842. [CrossRef]

7. Liu, B.; Li, X.B.; He, D.J.; Chen, L.; Pang, D.B.; Zhu, Z.Y.; Liu, L.Z.; Wu, M.Y.; Wu, Y.Q. Knowledge Mapping Analysis of Soil Respiration Research Based on Web of Science. Chin. J. Soil Sci. 2021, 52, 443-453. [CrossRef] 
8. Kosugi, Y.; Mitani, T.; Itoh, M.; Noguchi, S.; Tani, M.; Matsuo, N.; Takanashi, S.; Ohkubo, S.; Nik, A.R. Spatial and temporal variation in soil respiration in a Southeast Asian tropical rainforest. Agric. For. Meteorol. 2007, 147, 35-47. [CrossRef]

9. Ohashi, M.; Kumagai, T.; Kume, T.; Gyokusen, K.; Saitoh, T.M.; Suzuki, M. Characteristics of soil $\mathrm{CO}_{2}$ efflux variability in an aseasonal tropical rainforest in Borneo Island. Biogeochemistry 2008, 90, 275-289. [CrossRef]

10. Hanpattanakit, P.; Panuthai, S.; Chidthaisong, A. Temperature and moisture controls of soil respiration in a dry Dipterocarp forest, Ratchaburi Province. Kasetsart J. 2009, 43, 650-661.

11. Hanpattanakit, P.; Leclere, M.Y.; Mcmillan, A.M.S.; Limtong, P.; Maeght, J.L.; Panuthai, S.; Inubushi, L.; Chidthaisong, A. Multiple timescale variations and controls of soil respiration in a tropical dry dipterocarp forest, western Thailand. Plant Soil 2015, 390, 167-181. [CrossRef]

12. Wangluk, S.; Boonyawat, S.; Diloksumpun, S.; Tongdeenok, P. Role of soil temperature and moisture on soil respiration in a teak plantation and mixed deciduous forest in Thailand. J. Trop. For. Sci. 2013, 25, 339-349.

13. Tan, Z.; Deng, X.; Hughes, A.; Tang, Y.; Cao, M.; Zhang, W.; Yang, X.; Sha, L.; Song, L.; Zhao, J. Partial net primary production of a mixed dipterocarp forest: Spatial patterns and temporal dynamics. J. Geophys. Res. Biogeosci. 2015, 120, 570-583. [CrossRef]

14. Zhang, K. A preliminary study on the causes of climatic properties in Southern Yunan. Acta Meteorol. Sin. 1963, 33, 218-230.

15. Song, Q.; Tan, Z.; Zhang, Y.; Cao, M.; Sha, L.; Tang, Y.; Liang, N.; Schaefer, D.; Zhao, J.; Zhao, J.; et al. Spatial heterogeneity of soil respiration in a seasonal rainforest with complex terrain. Iforest-Biogeosci. For. 2013, 6, 65-72. [CrossRef]

16. Hanson, P.J.; Wullschleger, S.D.; Bohlman, S.A.; Todd, D.E. Seasonal and topographic patterns of forest floor $\mathrm{CO}_{2}$ efflux from an upland oak forest. Tree Physiol. 1993, 13, 1-15. [CrossRef]

17. Welles, J.M.; Demetriades-Shah, T.H.; McDermit, D.K. Considerations from measuring ground $\mathrm{CO}_{2}$ effluxes with chambers. Chem. Geol. 2001, 177, 3-13. [CrossRef]

18. Zhang, Q.; Katul, G.G.; Oren, R.; Daly, E.; Manzoni, S.; Yang, D. The hysteresis response of soil concentration and soil respiration to soil temperature. J. Geophys. Res. Biogeosci. 2015, 120, 1605-1618. [CrossRef]

19. Davidson, E.A.; Janssens, I.A. Temperature sensitivity of soil carbon decomposition and feedbacks to climate change. Nature 2006, 440, 165-173. [CrossRef] [PubMed]

20. Cai, Z.L.; Qiu, S.P. Seasonal variation of soil respiration and its impact factors in tropical seasonal rainforest in Xishuangbanna, Yunnan. Ecol. Environ. Sci. 2019, 28, 283-290. [CrossRef]

21. Schellekens, J.; Bruijnzeel, L.; Scatena, F.; Bink, N.; Holwerda, F. Evaporation from a tropical rain forest, Luquillo Experimental Forest, eastern Puerto Rico. Water Resour. Res. 2000, 36, 2183-2196. [CrossRef]

22. Kosugi, Y.; Takanashi, S.; Tani, M.; Ohkubo, S.; Matsuo, N.; Itoh, M.; Noguchi, S.; Nik, A. Effect of inter-annual climate variability on evapotranspiration and canopy $\mathrm{CO}_{2}$ exchange of a tropical rainforest in Peninsular Malaysia. J. For. Res. 2012, 17, 227-240. [CrossRef]

23. Bruijnzeel, L.; Veneklaas, E. Climatic conditions and tropical montane forest productivity: The fog has not lifted yet. Ecology 1998, 79, 3-9. [CrossRef]

24. Liu, W.; Wang, P.; Li, J.; Li, P.; Liu, W. The importance of radiation fog in the tropical seasonal rain forest of Xishuangbanna, South-west China. Hydrol. Res. 2008, 39, 79-87. [CrossRef]

25. Leff, J.W.; Wieder, W.R.; Taylor, P.G.; Townsend, A.R.; Nemergut, D.R.; Grandy, A.S.; Cleveland, C.C. Experimental litterfall manipulation drives large and rapid changes in soil carbon cycling in a wet tropical forest. Glob. Chang. Biol. 2012, 18, 2969-2979. [CrossRef]

26. Malhi, Y.; Baldocchi, D.D.; Jarvis, P.G. The carbon balance of tropical, temperate and boreal forests. Plant Cell Environ. 1999, 22, 715-740. [CrossRef]

27. Sayer, E.J.; Heard, M.S.; Grant, H.K.; Marthews, T.R.; Tanner, E. Soil carbon release enhanced by increased tropical forest litterfall. Nat. Clim. Chang. 2011, 1, 304-307. [CrossRef]

28. Hashimoto, $\mathrm{S}$. Temperature sensitivity of soil $\mathrm{CO}_{2}$ production in a tropical hill evergreen forest in northern Thailand. J. For. Res. 2005, 10, 497-503. [CrossRef]

29. Zimmermann, M.; Bird, M.I. Temperature sensitivity of tropical forest soil respiration increase along an altitude gradient with ongoing decomposition. Geoderma 2012, 187-188, 8-15. [CrossRef]

30. Fang, C.; Moncrieff, J.B. The dependence of soil $\mathrm{CO}_{2}$ efflux on temperature. Soil Biol. Biochem. 2001, 33, 155-165. [CrossRef]

31. Reichstein, M.; Beer, C. Soil respiration across scales: The importance of a model-data integration framework for data interpretation. J. Plant Nutr. Soil Sci. 2008, 171, 344-354. [CrossRef]

32. Kirschbaum, M.U.F. Seasonal variations in the availability of labile substrate confound the derived temperature dependence of heterotrophic respiration. Soil Biol. Biochem. 2013, 57, 568-576. [CrossRef]

33. Sha, L.Q.; Zheng, Z.; Tang, J.W.; Wang, Y.H.; Zhang, Y.P.; Cao, M.; Wang, R.; Liu, G.G.; Wang, Y.S.; Sun, Y. Soil respiration in tropical seasonal rain forest in Xishuangbanna, SW China. Sci. China D 2005, 48, 189-197. [CrossRef]

34. Peng, S.; Piao, S.; Wang, T.; Sun, J.; Shen, Z. Temperature sensitivity of soil respiration in different ecosystems in China. Soil Biol. Biochem. 2009, 41, 1008-1014. [CrossRef]

35. Yang, J.; Zhang, G.; Ci, X.; Swenson, N.G.; Cao, M.; Sha, L.; Li, J.; Baskin, C.C.; Ferry Slik, J.W.; Lin, L. Functional and phylogenetic assembly in a Chinese tropical tree community across size classes, spatial scales and habitats. Funct. Ecol. 2014, 28, 520-529. [CrossRef] 
36. Aguilos, M.; Takagi, K.; Liang, N.; Watanabe, Y.; Goto, S.; Takahashi, Y.; Mukai, H.; Sasa, K. Soil warming in a cool-temperate mixed forest with peat soil enhanced heterotrophic and base respiration rates but not $\mathrm{Q}_{10}$ remained unchanged. Biogeosci. Discuss. 2011, 8, 6415-6445. [CrossRef]

37. Kutzbach, L.; Schneider, J.; Sachs, T.; Giebels, M.; Nykänen, H.; Shurpali, N.J.; Martikainen, P.J.; Alm, J.; Wilmking, M. CO 2 flux determined by close-chamber methods can be seriously biased by inappropriate application of linear regression. Biogeosciences 2007, 4, 1005-1025. [CrossRef] 